\title{
Safety and Efficacy of Endoscopic Posterior Cervical Discectomy and Foraminotomy Using Three-Point Plaster Traction Technique
}

\author{
Jeong Hoon Kim${ }^{1}$, Nitin Adsul ${ }^{2}$, Hyeun Sung Kim², Sung Ho Choi ${ }^{1}$, Ki Joon Kim², Jee-Soo Jang ${ }^{1}$, Il-Tae Jang ${ }^{2}$
}

${ }^{1}$ Department of Neurosurgery, Nanoori Suwon Hospital, Suwon,

${ }^{2}$ Department of Neurosurgery, Nanoori Gangnam Hospital, Seoul, Korea

Corresponding Author: Hyeun Sung Kim, MD, PhD Department of Neurosurgery, Nanoori Gangnam Hospital, 731, Eonju-ro, Gangnam-gu, Seoul 06048, Korea

Tel: $+82-2-6003-9767$ Fax: +82-2-3445-9755

E-mail:

neurospinekim@gmail.com

Received: September 19, 2017 Revised: December 3, 2017 Accepted: December 12, 2017

\begin{abstract}
The endoscopic posterior cervical foraminotomy and discectomy have been continuously developed and are considered widely performed minimally invasive procedures while maximally preserving patients' anatomical structures. In posterior cervical spine surgery, the Mayfield head clamp is commonly used to provide a rigid, stable position of the head throughout the procedure. The use of the Mayfield head clamp has been associated with skull fractures, lacerations, air embolisms and epidural hematoma. However, we have performed 12 surgeries without Mayfield head clamp, in order to reduce the amount of equipment preparation needed and the additional risk of complications resulting from skeletal traction during surgery. These 12 patients were operated between January 2016 and February 2017 with full-endoscopic posterior discectomy or foraminotomy for posterolateral disc herniation or foraminal stenosis by osteophytes. In all 12 patients, preoperative average VAS scores were $7.67 \pm 1.4$ for the neck and $8.33 \pm 1.1$ for the arm, while postoperative VAS scores were 1.8 \pm 0.7 for the neck and 1.4 \pm 2 for the arm. All patients underwent a 6-month follow-up, during which improvement in VAS scores was maintained. There was no compromise in endoscopic view during surgery due to our positioning technique. Our results show that posterior cervical endoscopic spine surgery can be performed safely and effectively with three-point plaster traction technique without risks associated with skeletal traction.
\end{abstract}

Key Words: Cervical, Discectomy, Foraminotomy, Skeletal Traction, Endoscopy

\section{INTRODUCTION}

The prime indications for endoscopic posterior cervical foraminotomy are cervical radiculopathy that can be correlated to radiographic findings of posterolateral foraminal disc herniation or foraminal stenosis by osteophyte ${ }^{1,2)}$. Posterior foraminotomy and discectomy is a well-established technique for cervical radiculopathy, first described in the 1940s by Spurling and Scoville ${ }^{3)}$.

The advantages of endoscopic posterior foraminotomy and discectomy are it preserves the motion of the segment, as it is a non-fusion surgery. Exposure does not encounter vital anterior structures such as the trachea, esophagus, or carotid artery. Perioperative outcomes are comparable to posterior open foraminotomy in an appropriately selected patients ${ }^{4)}$. The surgical time, blood loss, analgesic use, and hospital stay are reduced in patients who underwent endoscopic procedure rather than open procedures ${ }^{5-8)}$.
In posterior cervical spine surgery, the Mayfield head clamp is commonly used to provide a rigid, stable position of the head throughout the procedure. The use of the Mayfield head clamp has been associated with skull fractures, lacerations, air embolisms and epidural hematoma ${ }^{9-13)}$. To avoid these reported complications of skeletal traction using Mayfield head clamp we performed these surgeries using three-point plaster traction technique. Here we present the safety and efficacy of this positioning technique in endoscopic posterior cervical spine surgeries.

\section{CASE REPORT}

Total 12 patients who were operated between January 2016 and February 2017 with full-endoscopic posterior discectomy or foraminotomy for posterolateral foraminal disc herniation or foraminal stenosis by osteophytes. Of the 12 patients, seven were male and five were female, and the average age was 52.1 (37-66) years. All 12 patients were suffering from neck pain 
and radicular pain at the time of their presentation with the involvement of either one or two levels (Table 1). All 12 patients were suffering from radiculopathy without any neurologic deficits. On admission, visual analog scale (VAS) scores were measured preoperatively and again determined after the surgery. Magnetic resonance imaging (MRI) was performed after the surgery in all patients to confirm the adequacy of decompression.

\section{Surgical Techniques}

The surgery was performed under general anesthesia with intraoperative fluoroscopy. Turning the patient from supine to prone was done with coordination of all operating room technicians. The anesthesiologist was primarily responsible for coordinating the move and for the repositioning of the head. We prefer a prone position on Wilson frame with slight reverse Trendelenburg. We used commercially available pillow of foam which supports the forehead, malar regions and the chin with a cutout for the eyes, nose, and mouth. The cervical spine was maintained with slight flexion by tilting down the head attachment of table and the head fixed in place with a plaster. The arms were adequately padded and tuck along the side of the patient. The legs were padded and flexed slightly at the knees and hips. The second plaster was applied to retract the shoulders and improve visualization of lower cervical spine on lateral fluoroscopy image. Excess traction was avoided on the shoulders as this may stretch the brachial plexus. The third plaster was applied on the back to reduce excessive skin folds (Fig. 1). This plaster traction technique is safer than skeletal traction using Gardner-Wells tongs ${ }^{14-16)}$ and easy to apply. We do not routinely use neuromonitoring during surgery.

A transverse incision of $8 \mathrm{~mm}$ was then made at the outer border of the interlaminar space, centering over the medial border of the facet joint. The obturator was inserted and docked at $\mathrm{V}$ point ${ }^{17)}$, the tip location is confirmed with fluoroscopy. We use an endoscope system with a 30-degree viewing angle, $7.3 \mathrm{~mm}$ outer diameter, and $4.7 \mathrm{~mm}$ working channel (Joimax $\mathrm{GmbH}$, Karlsruhe, Germany). The entire operation is performed under visual control and continuous irrigation with normal saline

Table 1. Characteristics of patients

\begin{tabular}{|c|c|c|c|c|}
\hline Patient & Age & Sex & Radiculopathy Side & Levels \\
\hline$A$ & 65 & $M$ & LT & C5-C6, C6C7 \\
\hline B & 66 & $\mathrm{~F}$ & LT & $\mathrm{C} 6-\mathrm{C} 7$ \\
\hline C & 52 & $M$ & LT & C5-C6, C6-C7 \\
\hline$D$ & 40 & $M$ & LT & C5-C6 \\
\hline$E$ & 45 & $M$ & LT & $\mathrm{C} 6-\mathrm{C} 7$ \\
\hline $\mathrm{F}$ & 37 & $\mathrm{~F}$ & RT & $\mathrm{C} 6-\mathrm{C} 7$ \\
\hline G & 45 & M & RT & C4-C5 \\
\hline $\mathrm{H}$ & 62 & $\mathrm{~F}$ & LT & C5-C6 \\
\hline । & 55 & $\mathrm{~F}$ & RT & C4-C5, C5-C6 \\
\hline J & 59 & $M$ & LT & C6-C7 \\
\hline K & 52 & $\mathrm{~F}$ & LT & C6-C7 \\
\hline $\mathrm{L}$ & 48 & $M$ & RT & C5-C6 \\
\hline
\end{tabular}

$(0.9 \%)$. The radiofrequency probe (Ellman's bipolar radiofre - quency electrocoagulator - Elliquence, Baldwin, New York, USA) is used to achieve hemostasis and the leftover muscles and soft tissue over the lamina are removed with a grasper. Once the soft tissue around the V-point is cleared, access window is created by the removal of bone around the $\mathrm{V}$-point using a long straight high-speed drill (Primado High-Speed Drill System - NSK, Nakanishi, Japan) and Kerrison rongeurs. Superior lamina, inferior articular process, inferior lamina, superior articular process are sequentially drilled to create a window of 6-8 $\mathrm{mm}$ diameter while the extent of the window may vary depending on the size and site of the herniated disc material. The outer border of the dura and exiting nerve root is identified after carefully removing the ligamentum flavum. The posterior foraminotomy is complete when the superior and inferior margins of the exiting nerve root are visible upto it's junction with the spinal cord. Ruptured disc fragments are identified and removed depending upon their location in shoulder, axilla or both of nerve root using micro-pituitary rongeur. After surgery, direct closure of the skin was done without any drain, subcutaneous tissue was sutured using 2-0 vicryl, and the skin was sealed with skin glue. All patients are advised to use a soft cervical collar for 15 days.

In all 12 patients, preoperative average VAS scores were 7.67 \pm 1.4 for the neck and $8.33 \pm 1.1$ for the arm, while postoperative VAS scores were $1.8 \pm 0.7$ for the neck and $1.4 \pm 2$ for the arm. These values indicate significant improvements in both neck pain and radiculopathy postoperatively (Table 2). All patients underwent a 6-months follow-up, during which improvement in VAS scores were maintained.

During surgery neither there was any issue pertaining to a patient position like a field of vision nor there was any complication postoperatively. The sufficient decompression was obtained

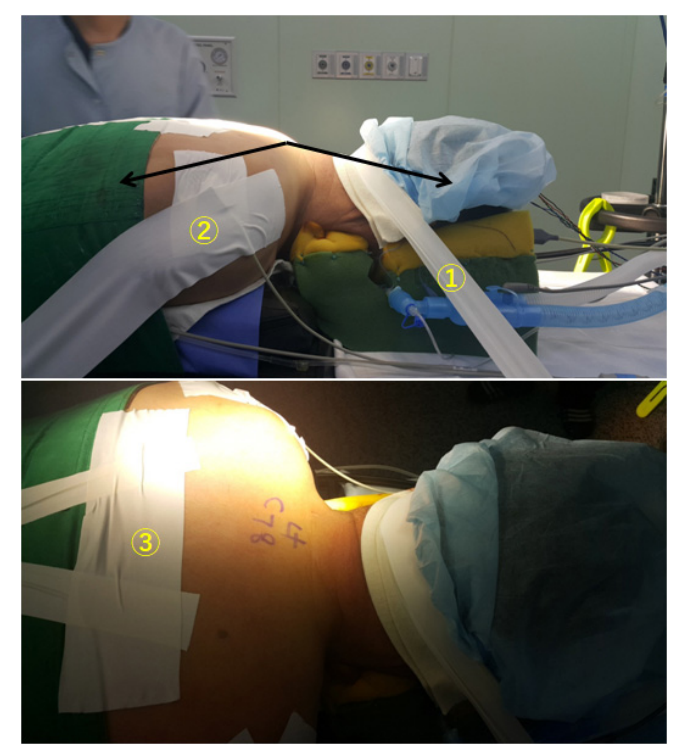

Fig. 1. Plaster traction technique for the patient position: 1- To fix the head, 2- To retract both shoulders, and 3- To reduce excessive skin folds. 
Table 2. Preoperative and postoperative VAS score

\begin{tabular}{cccccc}
\hline \hline \multirow{2}{*}{ Patient } & \multicolumn{2}{c}{ Preoperative VAS } & & \multicolumn{2}{c}{ Postoperative VAS } \\
\cline { 2 - 3 } \cline { 5 - 6 } Neck & Arm & & Neck & Arm \\
\hline A & 8 & 7 & & 2 & 2 \\
B & 6 & 8 & & 1 & 1 \\
C & 8 & 8 & & 2 & 2 \\
D & 8 & 7 & & 2 & 1 \\
E & 5 & 9 & & 3 & 1 \\
F & 8 & 10 & & 1 & 1 \\
G & 10 & 9 & & 3 & 2 \\
H & 9 & 8 & & 2 & 1 \\
I & 7 & 8 & & 2 & 2 \\
J & 6 & 9 & & 1 & 1 \\
K & 8 & 7 & & 1 & 2 \\
L & 9 & 10 & 2 & 1 \\
\hline
\end{tabular}

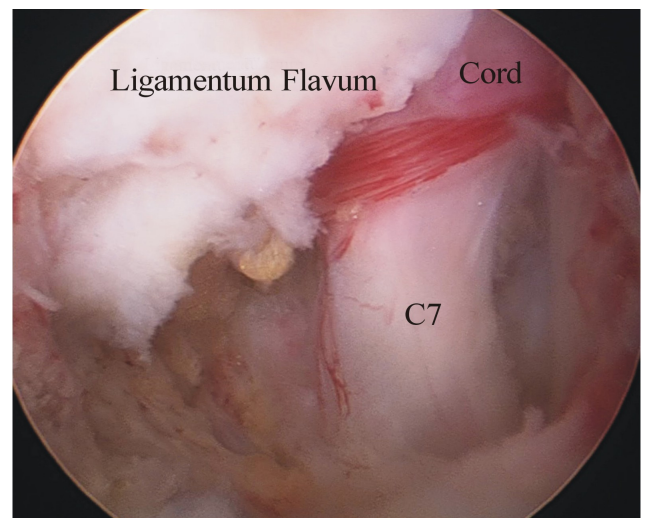

Fig. 2. Intraoperative endoscopic view. Adequate decompression of the ipsilateral nerve root after discectomy.

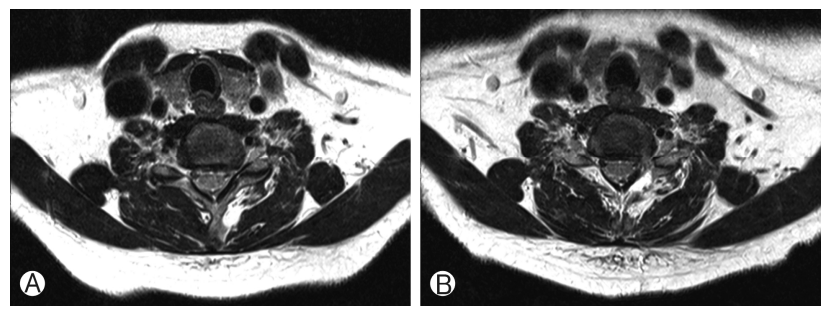

Fig. 3. Preoperative and postoperative MRI of a 66-year-old female patient. (A) Preoperative MRI showed left C7 nerve root was compressed due to foraminal disc. (B) Postoperative MRI showed the removal of herniated disc materials.

in all cases without any structural damage (Fig. 2). The decompression was further confirmed by postoperative MRI in all cases (Fig. 3).

\section{DISCUSSION}

Full endoscopic posterior cervical foraminotomy and discectomy procedure is one of the effective treatment methods for patients with unilateral radiculopathy due to cervical posterolateral disc herniation or foraminal stenosis ${ }^{14,15,18)}$. Rutten et al. reported a $96 \%$ success rate in laterally localized herniated cervical soft disc without instability in long-term follow up of two years ${ }^{2,14}$. In order to perform posterior cervical endoscopic spine surgery with such benefits, the existing surgical method fixes the position of patients' heads using skeletal traction. Therefore, in addition to the equipment required for endoscopy, additional equipment required specific for three-pin point fixation in order to complete the procedure. Performing three-pin point fixation lengthens the surgery preparation time and it is a frequent source of complications. Several devices can be used to immobilize the head, the most effective of which is the Mayfield head clamp. This clamp involves three-point pin fixation into the skull so that the skull and neck are rigid relative to the table and, assuming that the body is adequately secured to the table. Pin site complications include lacerations ${ }^{19)}$, skull fractures, associated intracranial hemorrhage (i.e., epidural, subdural, or subarachnoid hemorrhages), and infections that can lead to osteomyelitis ${ }^{20-25)}$

Therefore, in the current case series, we performed the surgery without skeletal traction. Neck flexion was relatively well maintained during surgery using our three-point plaster traction technique. Our results show that posterior cervical endoscopic spine surgery can be performed successfully with good clinical results without three-pin point fixation, which is beneficial to both patients and surgeons. There was no compromise in endoscopic view during surgery due to our positioning technique.

However, there is a need for greater surgical data on this technique, since in this case series, the surgery was only performed on 12 patients. Nevertheless, in these 12 cases operated without skeletal traction resulted in considerably good outcomes. Thus, we believe that three-pin point fixation using Mayfield head clamp is not absolutely necessary for endoscopic posterior cervical spine surgeries.

\section{CONCLUSION}

The endoscopic posterior cervical foraminotomy and discectomy have been continuously developed and are considered to be a widely performed minimally invasive procedure while maximally preserving patients' anatomical structures. We have obtained extremely satisfying results in our 12 patients without skeletal traction (Mayfield head clamp). Therefore, these surgeries using three-point plaster traction technique are safe and effective. However, these results must be confirmed in additional clinical cases using a longer follow-up period.

\section{Financial Disclosure}

No funds were received in support of this work.

No benefits in any form have been or will be received from a commercial party related directly or indirectly to the subject of this manuscript. 


\section{ACKNOWLEDGEMENT}

We would like to acknowledge scientific team members Ms. Jae Eun Park and Mr. Kyeong-rae Kim for providing assistance in acquiring full text articles and managing digital works.

\section{REFERENCES}

1. Ahn Y. Percutaneous endoscopic cervical discectomy using working channel endoscopes. Expert review of medical devices. 2016; 13(6):601-10.

2. Ruetten S, Komp M, Merk H, Godolias G. A new full-endoscopic technique for cervical posterior foraminotomy in the treatment of lateral disc herniations using 6.9-mm endoscopes: prospective 2-year results of 87 patients. min-Minimally Invasive Neurosurgery. 2007;50(04):219-26.

3. SPURLING RG. Lateral rupture of the cervical intervertebral discs: a common cause of shoulder and arm pain. Surg Gynecol Obstet. 1944;78:350-8.

4. Tomaras CR, Blacklock JB, Parker WD, Harper RL. Outpatient surgical treatment of cervical radiculopathy. Journal of neurosurgery. 1997;87(1):41-3.

5. Clark JG, Abdullah KG, Steinmetz MP, Benzel EC, Mroz TE. Minimally invasive versus open cervical foraminotomy: a systematic review. Global spine journal. 2011;1(1):009-14.

6. Scoville WB. Cervical disc: classifications, indication and approaches with special reference to posterior keyhole operation. Cervical spondylosis. 1981:155-67.

7. Kim K-T, Kim Y-B. Comparison between open procedure and tubular retractor assisted procedure for cervical radiculopathy: results of a randomized controlled study. Journal of Korean medical science. 2009;24(4):649-53.

8. Winder MJ, Thomas KC. Minimally invasive versus open approach for cervical laminoforaminotomy. Canadian Journal of Neurological Sciences. 2011;38(2):262-7.

9. Grinberg F, Slaughter TF, McGrath BJ. Probable venous air embolism associated with removal of the Mayfield skull clamp. Anesthesia \& Analgesia. 1995;80(5):1049-50.

10. Baerts WD, de Lange JJ, Booij LH, Broere G. Complications of the Mayfield skull clamp. Anesthesiology: The Journal of the American Society of Anesthesiologists. 1984;61(4):460-.

11. Lee M, Rezai AR, Chou J. Depressed skull fractures in children secondary to skull clamp fixation devices. Pediatric neurosurgery. 1994;21(3):174-8.

12. Pang D. Air embolism associated with wounds from a pin-type head-holder: Case report. Journal of neurosurgery. 1982;57(5): 710-3.

13. Yan H-J. Epidural hematoma following use of a three-point skull clamp. Journal of clinical neuroscience. 2007;14(7):691-3.

14. Kim CH, Chung CK, Kim HJ, Jahng TA, Kim DG. Early outcome of posterior cervical endoscopic discectomy: an alternative treatment choice for physically/socially active patients. Journal of Korean medical science. 2009;24(2):302-6.

15. Kim CH, Kim K-T, Chung CK, Park SB, Yang SH, Kim SM, et al. Minimally invasive cervical foraminotomy and diskectomy for laterally located soft disk herniation. European Spine Journal. 2015;24(12):3005-12.

16. Kim CH, Shin K-H, Chung CK, Park SB, Kim JH. Changes in cervical sagittal alignment after single-level posterior percutaneous endoscopic cervical diskectomy. Global spine journal. 2015; 5(1):31-8.

17. Won SJ, Kim CH, Chung CK, Choi Y, Park SB, Moon JH, et al. Clinical outcomes of single-level posterior percutaneous endoscopic cervical foraminotomy for patients with less cervical lordosis. Journal of Minimally Invasive Spine Surgery and Technique. 2016;1(1):11-7.

18. Youn MS, Shon MH, Seong YJ, Shin JK, Goh TS, Lee JS. Clinical and radiological outcomes of two-level endoscopic posterior cervical foraminotomy. European Spine Journal. 2017;26(9): 2450-8.

19. Nimityongskul P, Bose W, Hurley JD, Anderson L. Superficial temporal artery laceration. A complication of skull tong traction. Orthopaedic review. 1992;21(6):761, 4-5.

20. Copley LA, Pepe MD, Tan V, Dormans JP. A comparison of various angles of halo pin insertion in an immature skull model. Spine. 1999;24(17):1777.

21. Kameyama O, Ogawa K, Suga T, Nakamura T. Asymptomatic brain abscess as a complication of halo orthosis: report of a case and review of the literature. Journal of orthopaedic science. 1999;4(1):39-41.

22. Müller E, Wick M, Muhr G. Subdural abscess as a complication from use of the halo device. Der Unfallchirurg. 1998;101(8): 655-7.

23. Nottmeier EW, Bondurant CP. Delayed onset of generalized tonic?clonic seizures as a complication of halo orthosis: Case report. Journal of Neurosurgery: Spine. 2000;92(2):233-5.

24. Voor M, Anderson R, Hart R. Stress analysis of halo pin insertion by non-linear finite element modeling. Journal of biomechanics. 1997;30(9):903-9.

25. Williams FH, Nelms DK, McGaharan KM. Brain abscess: a rare complication of halo usage. Archives of physical medicine and rehabilitation. 1992;73(5):490-2. 